\title{
Book Review: Mycophilia. Revelations from the weird world of mushrooms
}

by Eugenia Bone. 2011 Rodale, Inc. New York, NY, USA. 348 pp.

ISBN 978-1-60529-407-0 (hard cover)

\section{Jorge A. Santiago-Blay ${ }^{1}$}

For years, I have been meaning to learn mycology so that my appreciation and perhaps knowledge of these relatively little explored creatures would allow me to be a better teacher, researcher, and editor. I decided to get started with those I "know", mushrooms. After all, I have eaten them in pizzas and have smelled the air surrounding areas where they are cultured. However, the catalyst for this new adventure was taking a look at fungi in amber. After inquiring about online courses in the science of fungi, mycology, I got an introduction by reading Eugenia Bone's Mycophilia.

According to Bone, only $5 \%$ of an estimated 1.5 million extant species of fungi have been described and they may represent $25 \%$ of the world's biomass. Also, fungi include some of the largest and tiniest eukaryotes (and some of the oldest) are fungi. Mycophilia reveals the adventures of the author in her path to learn about fungi. Knowledge of their biology is vital as we better avoid some of the 400 species of poisonous fungi, including a few deadly species of Amanita, such as A. muscaria (L.:Fr.) Lam. (Basidiomycota: Amanitaceae). In 1897, Count Achilles de Vecchj, an Italian diplomat in Washington, District of Columbia, USA, died from eating the fly agaric. I cannot but wonder if that event contributed to lasting fears about mushroom hunting that some people have shared with me in the USA. Other deadly species include Gyromitra esculenta (Pers.) Fr. (1849) (Ascomycota: Discinaceae) and species of the genus Cortinarius (Basidiomycota: Cortinariaceae). Finally, let us not forget that fungi

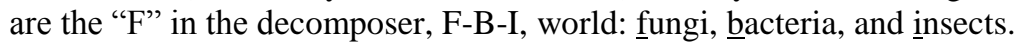

We encounter mushrooms in our daily lives. Although some fungi have been favorite culinary species for many since times immemorial, Mycophilia emphasizes the importance of distinguishing between friend and foe when it comes to interacting fungi. If we eat shiitake mushrooms, we taste their "savoriness" owing to umami, the fifth basic taste, which is also present in ripe tomatoes and many other foods. Just as Bone's candid narration of her motivations for joining the New York Mycological Club, many of her mycological-sociological adventures are hilarious. As she, I am also aware of the world of edible mushroom hunters ... and all the memories of past students those trips bring me. Morels, Morchella sp. [particularly M. esculenta Fr. (Ascomycota: Morchellaceae), over $40 \mathrm{~K}$ hits on the web for images of this

\footnotetext{
${ }^{1}$ York, Pennsylvania, USA. E-mail: blayjorge@gmail.com
} 
species], are edible mushrooms particularly sought after although, behold, 0.5$1 \%$ of mycetismus, poisoning by eating fungi reported in the USA, with only $1 \%$ of them culminating in death. Then, suddenly, the reader is catapulted into the world of exudate-oozing fungi, such as Lactarius (Basidiomycota: Russulaceae), commonly known as candy caps, some of which are edible.

Have you ever wondered how people outside of your own neighborhood use their time? Interestingly, a lot of what happens, including mycological hunts, rarely makes it to the national or international news. Instead, it is publicized in the more regional or local media. Sometimes, rather quietly, groups of people with common interests meet in church basements, schools, cultural centers, etc. to learn about their favorite subject matter and socialize.

After reading Mycophilia, I have begun studying a phenomenal mycology DVD I got a hold of the other day and hope to one day be ready to tackle the fungi I am less familiar with, such as those that engage in fascinating relationships with arthropods and others involved multitrophic interactions, such as those in the rhizosphere, or those associated with the phylloplane, or learning about the fungi that produce statins that help us some of us keep our blood cholesterol levels in check, and be "forever young". After all, this review was started in Hershey, Pennsylvania, a place I like to call the capital of chocolate in the universe! Even fungi have something to do with the making chocolate! Now, I see fungi everywhere, including those in amber. Know your fungi!

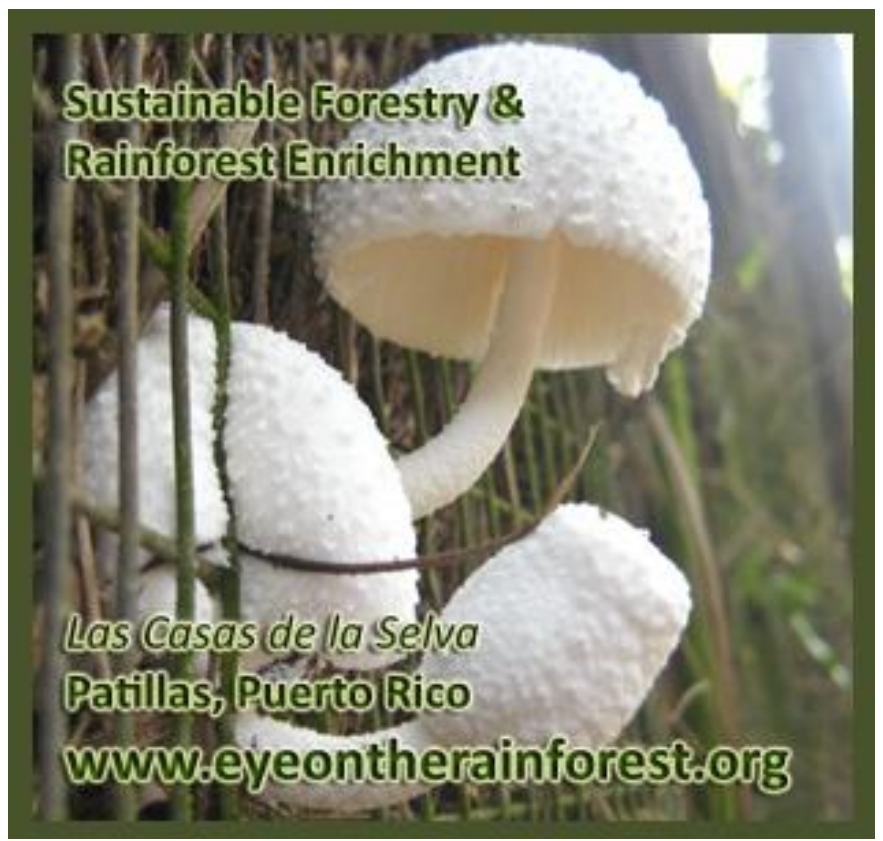

